\title{
Discerning Success of Indigenous Health Students in Community-based Programs
}

\author{
Marti Harder \\ Vancouver Island University, marti.harder@viu.ca \\ Barbara Astle \\ Trinity Western University, barbara.astle@twu.ca \\ Sonya Grypma \\ Trinity Western University, sonya.grypma@twu.ca \\ Evelyn Voyageur \\ Aboriginal Nurses Association of Canada, North Island College, evelyn.voyageur@nic.bc.ca
}

Follow this and additional works at: https://qane-afı.casn.ca/journal

Part of the Bilingual, Multilingual, and Multicultural Education Commons, Health and Physical Education Commons, Other Education Commons, and the Other Nursing Commons

\section{Recommended Citation}

Harder, Marti; Astle, Barbara; Grypma, Sonya; and Voyageur, Evelyn (2016) "Discerning Success of Indigenous Health Students in Community-based Programs," Quality Advancement in Nursing Education - Avancées en formation infirmière: Vol. 2: Iss. 2, Article 5.

DOI: https://doi.org/10.17483/2368-6669.1076

This Article is brought to you for free and open access by Quality Advancement in Nursing Education - Avancées en formation infirmière. It has been accepted for inclusion in Quality Advancement in Nursing Education - Avancées en formation infirmière by an authorized editor of Quality Advancement in Nursing Education - Avancées en formation infirmière. 


\section{Introduction}

When envisioning the future of Indigenous health care education, Villeneuve and MacDonald (2006) foresaw that more community-based health care programs would be established in Canada. In community-based health care programs (hereafter "community-based programs"), Indigenous students are able to remain living in their home communities while pursuing an education (Malatest, 2010). Graduates from community-based programs are more likely to seek employment within that same community upon program completion (National Aboriginal Health Organization, 2006). Here, "community" refers to a student's geographical home region, the population of which may consist of both Indigenous and non-Indigenous persons.

Part of the impetus of community-based programs is to meet local demands for qualified health care personnel. The need for Indigenous health care personnel is well documented, as are the high attrition rates of Indigenous students in health care programs (Anonson, Desjarlais, Nixon, Whiteman, \& Bird, 2008; Pijl-Zieber \& Hagen, 2011). Yet, while attrition rates provide one measure of student success (or rather, lack of success), they do not provide insight into how success is understood, supported, or accomplished within Indigenous contexts. This is best achieved by examining how student success is described and understood by community members where educational programs are delivered. Drawing on the perspectives of community members provides a fuller and more nuanced understanding of success, and how best to achieve it.

\section{Background}

The history of Indigenous students within the Canadian educational system, and especially the forced attendance at residential schools, is complex and traumatic, and cannot be ignored when studying Indigenous education (Canadian Council on Learning [CCL], 2007; PijlZieber \& Hagen, 2011). The effects of the history of Indigenous education in Canada will likely be felt for many years (Battiste, 2013). Because of the history of the residential school system and separation from family, Indigenous students may be fearful of seeking an education away from home (Holmes, 2005; Stonechild, 2006). For this reason, community-based programs may be seen as a more favourable option for education due to students not having to move from their communities to attend school.

While literature on community-based programs specifically related to Indigenous students is not plentiful, the extant literature suggests that such programs reduce some of the barriers students face during their education (Gregory \& Barsky, 2007). Gregory and Barsky's report on Aboriginal nursing in Canada, for example, suggests that "flexible programming" ( $p$. 25 ) enhances progression in nursing programs. Similarly, Malatest's (2010) study of retention of Aboriginal students in Ontario found that community-based education promotes success by eliminating relocation costs and providing students with their support systems as they remain living in their home communities. Furthermore, the Indigenous Adult Higher Learning Association (IAHLA) (2011) toolkit emphasizes the "historical disruption of family units" (p. 6) that occurred when students had to move away from home for schooling in the past, identifying community-based education as one approach to prevent this from occurring. In their review of the literature about Aboriginal students in health programs in Saskatchewan, Wilson and Sarson (2008) found that Saskatchewan has a "relatively large number of community-based education- 
related postsecondary programs that target Aboriginal peoples in the north [and that] most graduates of these programs have found employment in the north" (p. 122).

Descriptions of student success, particularly from a community-based education perspective, are not clearly established in the literature. A few researchers found that students describe success as discovering self and being able to help others in their community (Juntunen et al., 2001; Villegas, 2009). In Juntunen et al.'s qualitative study of American Indian students, measures of success are described as finding happiness and achieving goals. Villegas had similar findings in her qualitative study of Alaska Native educational leaders, adding that students also emphasized the importance of providing for one's family.

Several researchers suggest that there are barriers that make it difficult for Indigenous students to complete programs. Anonson et al. (2008) list difficult home lives, academic challenges, and different languages as examples of barriers to student enrollment, as well as successful completion of nursing education programs in Saskatchewan, Canada. They identify student and family support as necessary to promote student success and to overcome the barriers. Wilson, McKinney, and Rapata-Hanning (2011) identified similar barriers in their study of Māori nursing students in New Zealand, adding that family commitments contribute to tensions in the educational process, meaning students must sometimes make difficult choices between family needs and academic requirements.

In Canada, educational success of Indigenous students cannot be fully understood outside of a historical context of Indigenous education. The residential school system, created and administered by the Canadian government from the late 19th to the late 20th centuries, forcibly removed Indigenous children from their families and communities for years at a time, placing them in boarding schools ("residential" schools) with the intention of assimilating them into Euro-Canadian culture and society. The harmful intergenerational impact of the residential school system is still being felt (Smith, Varcoe, \& Edwards, 2005). For example, residential schools caused "irreversible changes within Aboriginal society" including "a direct impact on the mental and physical health and wellbeing of Aboriginal people today" (Waldram, Herring \& Young, 2006, p. 15). Furthermore, a century of residential schooling resulted in Indigenous peoples having great mistrust for the educational system (Battiste, 2013; Pijl-Zieber \& Hagen, 2011). Colonization, together with the oppression of Indigenous culture, effectively destroyed Indigenous education systems and caused students to doubt their abilities (Battiste, 2013).

Community-based programs are, in part, a response to the legacy of residential schools. They acknowledge the importance of remaining in one's community by aiming to educate students in the communities where they reside (IAHLA, 2009). As with "trauma-informed education" where respectful, empowering practices work towards hope, healing, and well-being (Browne et al., 2012; Mordoch \& Gaywish, 2013), community-based programs have the potential to build capacity and maximize Indigenous student potential.

This study was conducted in a northern community in Canada. The community has a population of approximately 600 Indigenous and non-Indigenous peoples and is made up of several small villages, and one slightly larger center, in close proximity to each other. All of the smaller villages receive their services, for example, education and health care, in one central location. An Indigenous Education Society (IES) is in place in the community, which provides post-secondary educational programs to community members. The IES is a non-profit 
organization, which receives federal government funding. The selection of this community, for this study, was influenced by the first author's professional working relationship with the IES. In the past, the IES has partnered with Public Post-secondary Institutions (PPSI) to deliver various educational programs, for example, practical nursing, health care assistant, and adult upgrading within their community. In 2008, the First Nations Education Steering Committee advised that such partnerships provide the mechanism to offer community-based programs. When entering into such educational partnerships, the IES and the PPSI work together to ensure that student supports are in place that will best promote student success.

\section{Purpose}

The purpose of this study was to explore how members of a community with a community-based program describe student success and the factors that influence it. The study was guided by three research questions: (1) How do Indigenous students and community stakeholders describe success in community-based programs? (2) What factors are viewed as influencing student success in these programs? and (3) In what ways can Indigenous student success be promoted?

\section{Method}

This qualitative study used an inductive methodological approach called "interpretive description" (as per Thorne, 2008) and was informed by concepts from Indigenous decolonizing perspectives (as per Smith, 2012). Interpretive description encourages researchers to uncover opportunities to deconstruct prior knowledge, and to generate new insights that provide understanding of a specific context. It is considered to be a method of particular value to nursing research in that it is concerned with findings that are useful or applicable in nursing practice (Thorne, 2008). In addition, interpretive description is well suited to smaller-scale qualitative investigation, which fit with this study (Thorne, Reimer Kirkham, \& O’Flynn-Magee, 2004).

The interpretive description methodology directly complemented the underlying Indigenous decolonizing concepts within the study by acknowledging that multiple realities exist. What does it mean to decolonize? Yellow Bird (2013) expressed that decolonization "refers to activities that weaken the effects of colonialism, facilitate resistance, and create opportunities to promote traditional practices in present-day settings" (p. 298). But how can decolonization be carried out in research? Conducting research from a decolonizing perspective honours Indigenous ways of sharing knowledge, including an expectation that researchers will share findings with Indigenous communities (Smith, 2012). In the past, research that involved Indigenous participants often incorporated relations of power and resulted in Indigenous peoples becoming "excluded, marginalized and "Othered"' (Smith, p. 35). Such sharing of knowledge requires a relationship between the researcher and the participants, and one of the key elements of the relationship is reciprocity. This study was designed with the recognition that the authors must be aware of the influence of power and work with Indigenous peoples in empowering ways, that there should be reciprocity in the relationship, and that the research should benefit the community (Smith, 2012). Vukic, Gregory, and Martin-Misener (2012) indicated that there is no one single Indigenous perspective, but the principles of Indigenous research require a process of "dialogue, community, self-determination, and cultural autonomy" (p. 154). To ensure that the community was involved in decisions related to the study design, the lead author, who was well known in the community, engaged in dialogue with key IES members-for example, who would 
participate in the study. Such an approach promoted reciprocity between the lead author and the community, and helped to promote respectfulness among those involved.

The Tri-council Policy Statement, which involves research on the First Nations, Inuit and Métis peoples of Canada (Government of Canada, 2015), was followed for this study. Ethics approval was obtained from the University's Ethics Board, together with Letters of Permission from relevant organizations, including the Indigenous Education Society (IES) and the Indigenous Health Centre (IHC). Permission was readily granted to conduct the study within this community. The IES followed the research process carefully and facilitated the selection of the study participants.

\section{Sample}

Convenience and purposeful sampling were used by the lead author and the Indigenous Education Society (IES) to invite study participants. Inclusion criteria included (1) individuals who worked at the IES or an Indigenous Health Centre (IHC) and who had been involved with the education of past health care students in the community; or (2) individuals who were former IES health care students or family members of former students. The two groups of participants were categorized as (1) "community stakeholders" or (2) "graduates or family".

The sample was comprised of eight participants including four community stakeholders, and four graduates or family. Community stakeholders included a Registered Nurse, an education administrator, an English instructor, and a retired Licensed Practical Nursing instructor. Graduates or family included two Licensed Practical Nurses, one Health Care Assistant (all of whom were former community-based students), and a parent of a former student. All participants were female, and their ages ranged from 21-73. Two participants were Caucasian while the remaining six identified themselves as First Nations, Aboriginal, or by the name of the First Nation into which they were born. Discussion occurred between the lead author and with the IES about the inclusion of an Indigenous Elder, as a participant; however, the intended Elder passed away prior to the commencement of the study. The community members gave permission to commence with the study with the understanding that the lead author would work in close relationship with the IES.

\section{Data collection}

Data collection consisted of individual semi-structured interviews conducted by the first author in a location convenient for the participants. The interviews focused on questions around the participants' educational experiences, for example, "When you hear the terms 'successful Indigenous students', what comes to your mind?". Written informed consent was obtained from all participants. All interviews were audio-recorded and transcribed verbatim by the first author. Participants were provided with a small gift as an expression of appreciation for their time.

\section{Data analysis}

In adherence to the methodology of interpretive description, concurrent data collection and an inductive data analysis approach were used. Data analysis began after transcription of the first interview. Repeated immersion in the data was achieved by reading and re-reading the first transcript and writing reflexive notes, before developing a preliminary code book in consultation with one of the other authors. Immersion in the data of subsequent interviews continued over several weeks, and then each of these transcripts was coded separately and comparisons were 
made across the whole data set looking for relationships between instances in the data (Thorne, 2008). Through this in-depth immersion, the data were organized into categories that had similar patterns for the purpose of interpreting meaning that could be applied to the data. A thematic analysis diagram was developed to help explore the themes as they were discovered. This process of analysis required continued extensive immersion with the data, and included several discussions with one of the other authors to ensure that validity was upheld. To conclude this process, a secondary literature review was conducted to compare the study findings with that of previous research. This inductive iterative approach allowed for a thorough exploration of student success in community-based programs. Through analysis of the data, the core theme of courage and the categorical themes of nurturing the learning, owning the learning, and discerning success for learning emerged. In the analysis process, the findings were organized and reorganized to explore the descriptions and experiences of success.

A variety of steps were taken to enhance the scientific quality of the study. A reflexive journal was maintained to evaluate how any personal beliefs may have influenced the interpretation of the data. Ongoing contact between the authors provided further discussion on emerging themes and categories. Field notes were written after each interview to analyze the interview process (Polit \& Beck, 2012), which included reflections in relation to the interviews. An audit trail was maintained to document decisions made by the authors, which allowed for critical reflection of the conclusions about the data. At the completion of the study, one of the authors, who is an Indigenous Elder, provided feedback to the final interpretation of the findings.

Person triangulation of data sources was accomplished by interviewing different types of participants (i.e., health care professionals, educators, graduates, an administrator, and a family member of a graduate). Furthermore, the use of the interpretive description methodology requires a thought-out frame of reference, a communication style designed to build rapport, and an allowance for altering initial interpretations (Thorne, 2008). In addition, Indigenous decolonizing concepts require the honouring of Indigenous knowledge, reciprocity within the relationship, and an awareness of the influence of power (Smith, 2012).

\section{Findings}

A core theme and three categorical themes were identified through the process of data analysis. The core theme of courage was seen as an essential trait within students in order to achieve success. Three categorical themes of nurturing the learning, owning the learning, and discerning success for learning were identified as descriptions of success and how to foster it in community-based programs. See Figure 1 for a thematic diagram portraying the core theme and categorical themes. 


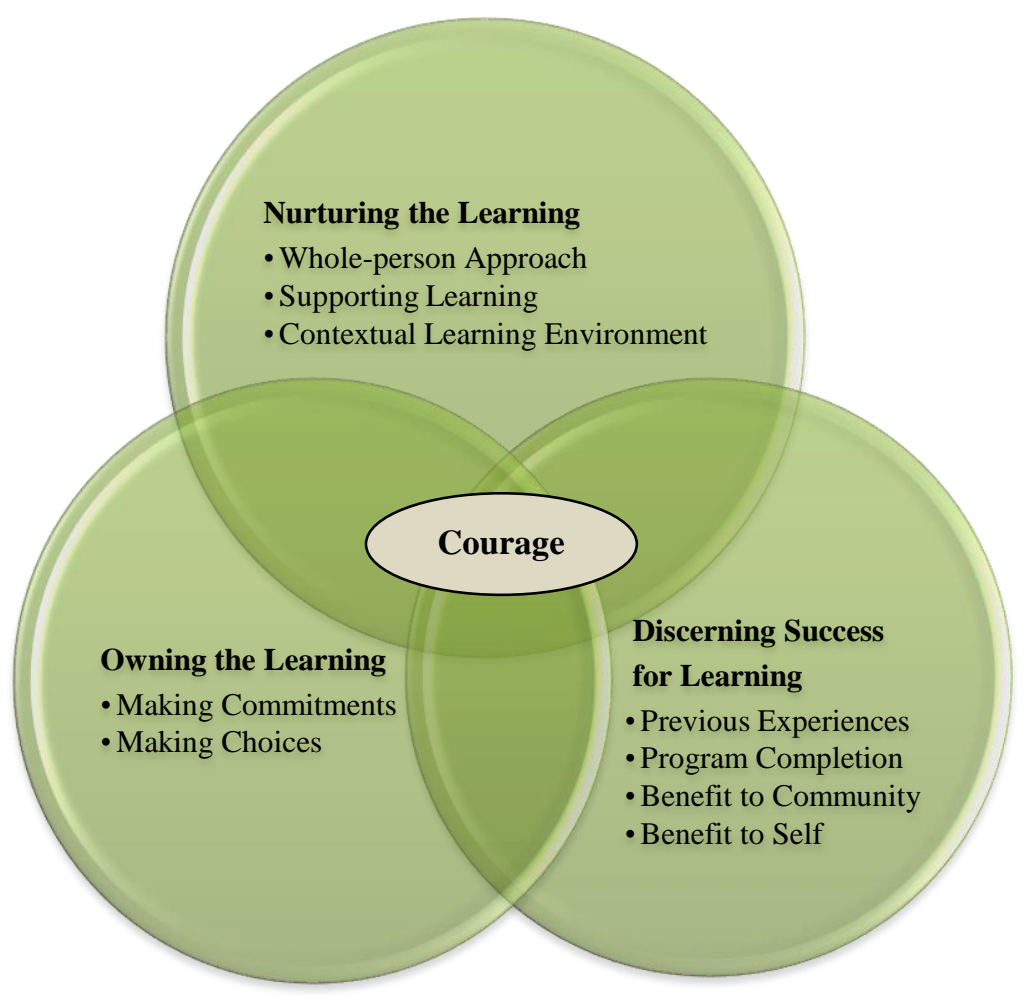

Figure 1. Discerning Success Thematic Diagram.

\section{Core Theme: Courage}

During the data analysis, a strong core theme of courage was identified. Both community stakeholders and graduates identified the importance of courage, including examples like courage to seek education, reduce reliance on Social Assistance, leave abusive relationships, and move forward to a life where they were independent and "able to stand on their own two feet." In other words, it took courage for students to make the necessary decisions to overcome barriers in their education journeys, from the time they decided to embark on an educational program to graduation itself. The core theme of courage informs the findings as a whole.

\section{Theme One: Nurturing the Learning}

Nurturing the Learning refers to the way in which students were supported by the community. It includes three sub-themes: whole-person approach, supporting learning, and contextual learning environment. As an example of the whole-person approach, a community stakeholder referred to the Indigenous Medicine Wheel and how the IES worked towards developing "balanced, healthy students" (8). All of the participants spoke about the lengths that the IES went to in order to acknowledge student circumstances, and suggested that assisting students with those circumstances was key to the learning process. A stakeholder explained "once you take care of the basic needs of these students, then the learning happens... [the IES will] take care of everything from there, basically" (4). A stakeholder asserted that there were many personal issues among the students, and that the role of the IES is to "build up people", to "mend the broken down spirits of the students", and to "nurture that spirit" (8). The IES was also described as supporting students financially. A stakeholder referred to a student who didn't have 
the finances to pay tuition at the start of the program, stating that "it was the end of the year before [the student] paid. So that was nice because they [the IES] didn't hound [the student] or anything" (6).

In addition to accommodating student circumstances from a whole-person approach, supporting learning was also found to nurture learning. Several participants stressed the need to have someone express a belief that the student could be successful in his/her education. A graduate described her learning journey and stated "having somebody believe in you [...] just one person [...] then from there, you've gotta believe in yourself that you can do it. 'Cause if nobody believes in you, then you don't believe in yourself' (7). This graduate credited the support she received from her spouse: "my partner really supported me: "you can do this"” (7). Other participants received support from their teachers that kept them going in their learning journeys. A community stakeholder encouraged students by stating "I don't know if anybody's ever told you this, but you can actually be anything you want to be, like anything" (4).

The contextual learning environment was nurtured learning in relation to safety and comfort. This sub-theme refers to several types of safety evident in the data: the welcoming and safe environment at the IES, the familiarity of learning in one's home community, personal safety, and safety in relationships. A community stakeholder stated that students "felt safe and comfortable" at the IES, and "when you're safe and comfortable, you know, learning kind of happens" (4). Several participants referred to the safety of learning in their own community, and a graduate noted that "for people like me who have small children, it's easier to have it here "cause you have the support of your family, and you don't have to move" (3). Participants also shared how the IES encouraged personal safety in students' homes by building capacity and courage to make changes if necessary. For example, a stakeholder urged a student by stating "now you're in a position to make the change [...] you can break away from that man if you need to because of how abusive he is [...] you don't have to be living in fear" (8). Finally, participants referred to the safety in relationships that the IES strives to make with nonIndigenous cultures in the community, and how students from all cultures were welcome to participate or attend events: "our doors are open to anybody" (8).

\section{Theme Two: Owning the Learning}

Owning the Learning refers to students' self-determination in the educational process. It includes the sub-themes making commitments and making choices. Making commitments refers to students being dedicated to their educational goals and trying not to let other events disrupt their learning trajectory. For example, one community stakeholder shared a story about a student who continued coming to classes despite having to move to a transition house (a safe home for women who are in abusive relationships) partway through the program. The transition home was one hour away, but the student "didn't miss any school. She came all the way to school. The student persevered, stating insistently “'I'm keeping up. I'm doing this. I'm getting this. I'll be independent [...] if this [situation at home] doesn't get resolved, I can support myself and my girls"' (1). The community stakeholder praised the student's determination and commitment to the program. IES staff noted that they were more likely to support students when needs arose if they saw that students were committed to their schooling, and put in the effort to meet program requirements. Likewise, if the IES worked above and beyond to support students, they expected students to put a high level of effort into their schooling. As one community stakeholder said, "we will bend over backwards for students if they're serious. But they have to be serious" (4). 
The sub-theme of making commitments is related to the second sub-theme, making choices, in that students are seen as having a choice regarding the level of commitment they give to their studies. However, making choices goes further in the sense that students continually make choices in both their education and their life in general. Community stakeholders and graduates emphasized the notion that students have to constantly choose between paths. Examples of choosing a path include coming to school versus missing classes, attending school despite living in an abusive environment at home, and remaining on Social Assistance versus getting an education and subsequently becoming employed. The participants also spoke about taking control of their own lives as opposed to being restricted by other influences, for example, individuals being on Social Assistance and being required to attend courses in which they were not interested, or being on Social Assistance and not having the finances to improve the living conditions of their families. Finally, participants spoke about choosing to be a positive role model for others.

One community stakeholder summed it up by stating that only students "can make it work. Not the instructors, not your fellow students. You" (1). Similarly, one graduate noted that ultimately it was she who had to make the choice to delve fully into the program. While she acknowledged that encouragement from others got her through the front door at the IES, it was her own effort that saw her through: "I did the rest" (7).

Graduates discussed the concept of making choices in order to move forward with their lives. For example, two participants noted that, prior to attending the program they, like many families in the community, relied on Social Assistance (SA) for their livelihood. For one, giving up her dependence on SA as part of her participation in the program gave her opportunity to move out of poverty. That is, education eliminated her dependence on SA, opening the doors to self-determination and personal success. "For me," she reflected "I'm just happy that I did something with my life. I was on SA. [In contrast] success is getting yourself on your feet and going the right path" (7).

By making choices with regard to their educational programs - and, by extension, their self-determination-students' actions propelled them into the status of being role models in the community. As one graduate stated:

A lot of the students have graduated and they're working here in the community. They're working with the people and they're showing others that they can be successful with education, and provide for their families instead of living on welfare or just living in poverty altogether... because a lot of people in our communities do live in poverty. (3)

\section{Theme Three: Discerning Success for Learning}

Discerning Success for Learning refers to ways in which participants understood and expressed the concept of student success. This theme includes several sub-themes: the effect of previous educational experiences, program completion or non-completion, the benefit to the community, and benefit to self.

In terms of previous educational experiences, both community stakeholders and graduates described the impact of both positive and negative educational experiences on their approach to health care education. Those previous experiences affected their view of education 
as a whole and gave a sense of how to grow beyond negative experiences. A graduate spoke about her high school years, and how they left her fearful:

As a young person growing up in this community, going to high school, I remember feeling like I wasn't good enough [...] my self-esteem was low [...] I remember having that block, not having that vision of success, not having that support [...] And I failed. I only got to grade 11 . When I was going into grade 12 , I thought 'there's no use for me, succeeding and going to graduate [...] So, I think through my personal experience, that fear was always there of success. (5)

For this participant, pursuing educational success was something to be feared.

The second sub-theme, program completion, emphasizes a conventional view of success as completing an educational program and graduating. Yet, on closer inspection, there were variations in the data that revealed nuances in the responses with regard to program completion as a sign of success. One of the community stakeholders, who was perhaps the most conventional in her response, insisted that "success means that students complete the program and work in the field" (1). Graduating was only part of the success: working in the field (and liking the work) is a more accurate sign of success. Another stakeholder mused that some students may not have been able to successfully complete a program because they weren't meant to be on that path, not because they were not successful. That is, those students should still be considered a success because they had the courage to attempt a program. She noted that sometimes students who were unsuccessful in one program were successful in another program because that is "where their interest was to begin with" (4). This broadened view of student success offers a critical counterpoint to the conventional view of attrition rates as the primary measure of student success.

The third sub-theme, benefit to community, points to one of the primary assumptions of community-based programs. To some, the raison d'etre of these programs is to educate local people who will work as health care professionals in the community where they studied. Participants spoke extensively about graduates now meeting the needs of the community, and how this was viewed as a success for the community as a whole. For example, one community stakeholder, who organized home health services in the community, noted that IES health care graduates who were employed in her clinic were responsible for providing wound care, diabetic teaching, foot care, and many other services to clients. To this participant, student success is "what we can give to the community [...] so that the community gets all of the [necessary health care] services" (2).

Positive feedback from clients is also a sign of success, as is positive relationships with community members. Having health care professionals who "can speak to the Elders in their own language" is a significant marker of success (4). Because the practicum experiences occurred within the community, students' education was visible to the entire community. When students graduated, the community "celebrated the success" with them, taking ownership of "their" new graduates (8). In this way, student success is a collective success; students are supported by the community, who in turn are supported by the skills and expertise offered by graduates as knowledgeable health care providers. It is a joint success, not just the success of individual students. 
The fourth sub-theme, benefit to self, moves the narrative beyond program completion, and even beyond benefit to the community. What participants most emphasized as an indicator of success was the personal growth and development of the students themselves. For example, one community stakeholder drew attention to the Medicine Wheel. Referring to the wellbeing of students, she defined success as "a balanced person [...] we want that person to blossom" (8). Similarly, another community stakeholder noted that a successful student was one who is balanced and living a healthy lifestyle (6). In addition, she described success as

the building up of people like a house with a solid foundation and the walls are solid brick. That would be their confidence, their self-esteem, their academic knowledge. And just feeling good about themselves, knowing that they can do it... success is the people that we've built up, the broken spirits that we've mended. (8)

She concluded that success was when students stood "on their own two feet, able to change their predicament [of difficult home lives]" (8).

Stakeholders and graduates alike identified increased confidence, independence, and selfesteem as indicators of success. One graduate stated that success is "being confident, being independent, having self-worth. Because I was on Social Assistance, I didn't believe I could do anything" (7). Another stressed that "believing in yourself" (5) was integral in her journey to success. Others identified still "being happy with where they're at" as a description of success (2, 5 and 7). As one graduate noted, "success is getting yourself on your feet and going down the right path, finding what makes you happy, and feeling confident" (7). In this way, student success is represented by an increased sense of confidence-including confidence to overcome fears-along with a sense of self-worth and independence.

\section{Discussion}

In line with the aim of interpretive description (Thorne, 2008) and Indigenous decolonizing concepts (Smith, 2012), the Indigenous Medicine Wheel has been chosen as a framework within which to guide the discussion of the study findings. The Medicine Wheel symbolizes dimensions of health and represents the alignment of different aspects of the whole person. It counters tendencies towards fragmentation and reductionism in data analysis, urging the researcher toward the whole by emphasizing, for example, the collective (community) over the individual (student or graduate). Following a brief overview of the Medicine Wheel, findings are organized below under three headings: the importance of taking a whole person approach, the importance of support and encouragement, and the importance of partnerships with community.

\section{Indigenous Medicine Wheel}

The Medicine Wheel has been used frequently as an educational model for cultural responsiveness to support Indigenous students (Assembly of First Nations, 2012; Pewewardy, 1999; Pijl-Zieber \& Hagen, 2011). Traditionally, the Medicine Wheel incorporates four equal, or balanced, planes of experience: mental, spiritual, emotional, and physical. Educators should engage each of these planes to promote healthy, balanced students (Pewewardy, 1999), and to nourish the learning spirit (Anuik et al., 2010). When holistic teaching is based on the Medicine Wheel, and each plane of experience is considered, students have the "opportunity to develop 
him/herself as a whole person" so that they are empowered "to undertake the learning necessary for their continued growth and development" (Hill, 1999, p. 97).

Within a Medicine Wheel framework, educators are seen as healers. They are required "to be introspective, to link awareness" (Pewewardy, 1999, p. 28) into their teaching practice. When educators teach from such a perspective, they would more likely be aware of individual student circumstances as they arise. Battiste (2013) stressed the need for holistic and humanistic connections, with educators being ever attuned to their students. Battiste further urged educators to "make educational opportunities for students that nourish their learning spirits and build strong minds, bodies, and spirits" (p. 100).

\section{The Importance of Taking a Whole-person Approach}

Most participants in this study spoke about how the Indigenous Education Society (IES) ensured that students were supported through a whole-person approach to be successful in their education. They referred to the Indigenous Medicine Wheel as a model to follow. The importance of supporting students through a whole-person approach has also been noted by others. For example, in their study of a remotely run Indigenous nursing program in the Torres Strait Islands, Usher, Lindsay, and Mackay (2005) identified the need to have a committee comprised of "local stakeholder representatives" that could "provide guidance on issues relevant to Indigenous student needs in that region" (p. 440). Similarly, Malatest (2010) noted that if Aboriginal students' social needs are unmet, it could prevent program completion.

Part of a whole-person approach includes taking into account the social context for learning. The Canadian Association of Schools of Nursing (CASN) (2013) identifies "contextual determinants of health" as a key component for delivering culturally safe and culturally competent nursing education among Aboriginal peoples. CASN identifies the importance of bringing "society, culture, history, and context alive throughout the program" (CASN, 2013, p. 9). This is precisely the intention of community-based programs. For example, in their Educational Partnership Toolkit, IAHLA (2011) noted that removing students from the community to attend school elsewhere can be "personally and culturally isolating" (p. 6). In the current study, participants identified how experiencing a context of safety and comfort supported learning - including the familiarity of learning in one's home community, personal safety, safety in relationships, and cultural safety. Graduates valued learning culturally relevant teachings within a culturally familiar environment. This aligns with Malatest's (2010) findings related to Aboriginal students in Ontario where, in community-based programs, culture shock and isolation can be avoided as "students continue to stay with their families and communities and are thus able to access their support" (p. 66).

While the importance of a sense of personal safety was identified by several of the participants in the current study, this is not a common theme in the literature, although Malatest (2010) referred to an "awareness that Aboriginal students, particularly women with children, have social needs that, if not met, will seriously impede academic program completion" (p. 73). The CASN (2013) framework identifies "a safe and supportive classroom environment for students" (p. 9) and calls upon educators to adopt approaches such as openness, respect, social justice, and inclusiveness to achieve this. In this study, acknowledging students' circumstances, and advocating for their personal safety appeared to be a particularly necessary aspect towards students' ability to become educated. 
The notion of cultural safety was evident in the findings, particularly with regard to the IES as an institution, and its relationships with the surrounding community. Cultural safety is understood as an important element of Indigenous education (Aboriginal Nurses Association of Canada, 2009; CASN, 2013; Smye, Josewski, \& Kendall, 2010). In a culturally safe environment, the perspective of Indigenous individuals is acknowledged first (Ramsden, 2002), and "alternative perspectives" are welcomed (for example, culturally diverse approaches to tasks or activities) (Kulig et al., 2010, p. 99). However, as Minore et al. (2013) found, content related to Aboriginal health often focuses on deficits, rather than strengths. In the current study, the IES was intent on developing a balanced curriculum that respected and honoured Aboriginal identity and traditions. This was, according to the participants, an important factor in the success of the program.

\section{The Importance of Support and Encouragement}

According to graduates in the current study, support and encouragement from others were a necessary component in their educational journeys. In this section, findings are categorized as the effect of previous experiences, encouragement and commitment from others, and believing in self and experiencing personal growth.

According to the Canadian Council on Learning (CCL) (2009), it is important to consider the effects of previous education on current learning experiences for Aboriginal students. Negative previous experiences affect the outcome of future learning. Although participants in the current study made only a few direct references to residential schools, residual effects of it were evident in the data in various ways, particularly the lack of parental encouragement for schoolaged children to attend school. Several participants had not completed high school as children, citing reasons such as lack of confidence and lack of belief in self. These graduates returned to school for high school upgrading in their adult years.

Aboriginal children who attended residential schools experienced trauma in the form of separation of parents and children, suppression of language and culture, and widespread physical and sexual abuse (Gregory, 2005; Smith et al., 2005). As a result, there are continued intergenerational effects of the past residential school system on Indigenous peoples' mental, social, and physical health. For this reason, some researchers are encouraging educators to teach from a trauma-informed perspective, with an awareness of the history of the intergenerational trauma and its effect on student behaviours and educational efforts (Collins Sitler, 2008; Mordoch \& Gaywish, 2013). Browne et al. (2012) explained that being trauma-informed does not mean that trauma histories need to be elicited, but rather that strategies are in place to actively minimize re-traumatization and to ensure that the learning environment is safe for students, with an understanding of the effects of the trauma.

Community stakeholders expressed how many of the students had never dreamt about a higher level of education because of assuming they would be unsuccessful. Participants described the courage it took for students to overcome such fears. The CASN (2013) framework for nursing education indicates that building respectful relationships and creating "a safe and supportive classroom environment for students" (p. 9) is necessary in learning environments.

Community stakeholders and graduates stressed the need for the encouragement and commitment of others, such as family, faculty, and others who believed in them to promote student success. Several participants indicated that if just one person believed in the student, that 
was enough to encourage the student to pursue further education. This finding supports the CASN (2013) framework, which advised educators to "build respectful relationships" (p. 9) with students. Instructor-student relationships are vital in promoting student success.

Community stakeholders and graduates expressed that students needed to own their learning, for example, making commitments and choices to promote success. Battiste (2013) further states that learners must be "nourished to succeed" (p. 180) until learning becomes "a self-directed path" (p. 181). Graduates considered themselves to be a success because they gained confidence, self-worth, independence, and a voice through their educational journey.

\section{The Importance of Partnerships with Community}

To Stansfield and Browne (2013), cultural safety orients "away from describing the cultural practices of the "Other"' (p. 5) and toward a focus on power imbalances and possible discrimination (Browne et al., 2009). Partnerships and relationships with the community where the programs were delivered were considered important by the participants. Although there were few direct references to postcolonialism and cultural safety, some evidence of these concepts was threaded through the relationships and interactions between Indigenous and non-Indigenous peoples in the community. Browne, Smye, and Varcoe (2005) argue that postcolonial perspectives highlight the need for partnerships within Indigenous communities. Participants alluded to power inequities between Indigenous and non-Indigenous peoples in the community when speaking about the need to "build bridges" between cultures.

\section{Program Completion or Non-Completion}

Perhaps one of the most interesting findings relates to participant views with regard to program completion versus non-completion. Some participants ascribed to the view that noncompletion of a program was considered a failure. Others, however, suggested that the experience of attempting a program could be considered a success for a few reasons. First, as mentioned earlier in this paper, accessing a program could in itself be considered a success. Furthermore, as some stakeholders noted, in some cases accessing a program gave the opportunity for a student to identify their gifts and talents. If students moved out of one program in order to access another, this was still considered a success.

On the theme of completion/non-completion as a measurement of success, Ambler (2005) noted that students are not necessarily considered to be successes even if they have earned honour roll grades or obtained jobs post-graduation. Rather, success can be viewed in combination with the transformation of the community after students graduate. Similarly, the CCL (2007) insisted that approaches to measuring success focus on particular stages of education (for example, graduation and attendance rates), but do not consider the holistic lifelong learning that is considered essential in Aboriginal culture. Rather than merely focusing on students finishing programs, the measurement of holistic learning, or "the development of the whole person... is integral to issues of cultural continuity, identity and, ultimately, successful learning" (CCL, p. 11). Following the Summit on Aboriginal Education, the Council of Ministers of Education, Canada (2010) concurred, stating that measurements of success beyond educational achievement are required for Aboriginal students, because "a holistic view of success is appreciated by First Nations, Métis, and Inuit peoples" (p. 15). Attrition then, as a marker of success or failure, does not fully capture meanings of success for Indigenous students and their communities. 


\section{Limitations}

The most obvious limitation of this study was that of the small sample size. With only eight participants from a single geographical region, some understanding of success was achieved, but caution would have to be used when attempting to transfer these findings to other populations. As requested by the community, the interviews took place over a short period of time, which may have limited the amount of reflexivity between interviews. As well, three of the four authors have had experience working with Indigenous peoples, but are not from Indigenous background, so the unconscious injection of bias into the data analysis could have occurred. One of the authors, however, is an Indigenous Elder, so may have been able to mitigate this limitation by contributing to the final analysis and interpretation of the conclusions of the study.

\section{Recommendations}

Five recommendations arise from this study. First, nurse educators should intentionally pursue strategies that allow Indigenous students to experience successes along the way in their educational journey, and particularly in the early stages of their education. Given that one of the greatest obstacles identified is "a lack of confidence" (Blanchfield, 2006, p. 40), a goal for new students might be to promote confidence and belief in self. This could include implementing various teaching modalities, such as short one-day workshops or seminars early in the program where there is a sense of success and completion at the end of the session.

Second, nurse educators should tap into the importance of nurturing learning. According to Pewewardy (1999), educators may be seen as healers in the classroom when they show awareness and introspection when supporting students. Educators would do well to become more culturally and trauma-informed. They must recognize and value the role of the broader community, and find ways to intentionally include Elders or other respected community members into the learning experience. According to McDonald (2010), nursing educators need to develop knowledge about curriculum, evaluation, and teaching-learning strategies. In community-based education, educators require culturally relevant knowledge (p. 131). Hiring local educators who are respected by the community is ideal, as recommended by Usher et al. (2005), as they might be more likely to understand the context within the community.

Martin and Seguire (2013) recommend that educators attend workshops that teach them how to "implement student-centered approaches" (p. 208) with Indigenous students. Martin and Kipling (2006) further recommend that faculty learn the history of Indigenous education in order to create healthy student-teacher relationships. Also, educators should be "aware of the cultural and family issues which may impact on the progression of Indigenous students" (Australian Nursing Federation, 2006, p. 2). Furthermore, educators should acknowledge potential power differentials related to historical colonial relationships between Indigenous and non-Indigenous peoples, and demonstrate cultural safety. Promoting relationships and trust between students and educators appears vital in supporting students to achieve a holistic understanding of education, one that draws on all four aspects of the Medicine Wheel.

A third recommendation is to explore experiences of nurse educators who teach in community-based programs, how they prepare themselves to teach Indigenous students in remote communities, and how they promote success. While this study included two educators as participants, it would be interesting to develop a study where the sample consisted entirely of educators. 
The fourth recommendation surrounds the concept of balance that was referred to in the data. Many participants spoke about the need for students to be healthy and balanced in their lives, so that effective learning could take place. A study to explore the meaning and experience of the concept of balance among Indigenous community-based students may provide more insight into this concept.

A fifth recommendation is in relation to the lack of inclusion of Indigenous Elders as participants in the study, although there was input from other community members. Cameron (2010) stated that the mentoring and guidance of Elders can promote the retention of Indigenous nursing students. Study into the influence and effect of Indigenous Elders on students' educational success may provide further insight into their learning.

\section{Conclusion}

This study explored how members of a community with a community-based program describe student success and the factors that influence it. The five main conclusions were as follows: 1) Finding the courage to overcome fears and barriers was instrumental in students' educational journeys. Students often had to make life-changing choices that required great courage in order to advance in their education; 2) Receiving nurturing through a whole-person approach appeared to promote success in students' learning journeys; 3) Students following their educational paths were fostered through the support and encouragement from instructors and family members; 4) Students learning to believe in themselves was a key element of success; and 5) When students were successful in completing a community-based program, the community was also perceived to be successful.

To summarize this study, it appears that students in community-based programs benefit from a nurturing learning environment through a whole-person approach, where encouragement is readily given. As students take ownership of their learning, they may begin to believe in their own abilities and move past previous fears of schooling. Ultimately, through the nourishing of the learning spirit, students can bloom into who they are meant to become, and it is then that success occurs. 


\section{References}

Aboriginal Nurses Association of Canada. (2009). Cultural competence and cultural safety in nursing education. Retrieved from www.cna-aiic.ca/ /media/cna/page-content/pdfen/first_nations_framework_e.pdf?la=en

Ambler, M. (2005). Tribal colleges redefining success. Tribal College Journal, 16(3), 8-9.

Anonson, J., Desjarlais, J., Nixon, J., Whiteman, L., \& Bird, A. (2008). Strategies to support recruitment and retention of First Nations youth in baccalaureate nursing programs in Saskatchewan, Canada. Journal of Transcultural Nursing, 19(3), 274-283. http://dx.doi.org/10.1177/1043659608317095

Anuik, J., Battiste, M., \& George, N. (2010). Learning from promising programs and applications in nourishing the learning spirit. Canadian Journal of Native Education, $33(1), 63-82$.

Assembly of First Nations. (2012). First Nations lifelong learning assessment report. Retrieved from www.afn.ca/uploads/files/education/first_nations_lifelong_learning_report.pdf

Australian Nursing Federation. (2006). Indigenous Australian people and nursing education: Joint position statement. Retrieved from http://anmf.org.au/documents/policies/RCNA_JPS_indigenous_nursing.pdf

Battiste, M. (2013). Decolonizing education: Nourishing the learning spirit. Saskatoon, SK: Purich Publishing Ltd.

Blanchfield, C. (2006). Centre of excellence would support Aboriginal nursing students. Canadian Nurse, 102(4), 15 \& 40.

Browne, A., Smye, V., \& Varcoe, C. (2005). The relevance of postcolonial theoretical perspectives to research in Aboriginal health. Canadian Journal of Nursing Research, 37(4), 16-37.

Browne, A., Varcoe, C., Smye, V., Reimer-Kirkham, S., Lynam, M., \& Wong, S. (2009). Cultural safety and the challenges of translating critically oriented knowledge in practice. Nursing Philosophy, 10(3), 167-179. doi:10.1111/j.1466-769X.2009.00406x

Browne, A., Varcoe. C., Wong, S., Smye, V., Lavoie, J., Littlejohn, D., ... \& Lennox. S. (2012). Closing the health equity gap: Evidence-based strategies for primary health care organizations. International Journal for Equity in Health, 11(1), 59. doi:10.1186/14759276-11-59.

Cameron, L. (2010). Supporting Indigenous nursing students. Australian Nursing Journal, $18(6), 39$.

Canadian Association of Schools of Nursing (CASN). (2013). Educating nurses to address socio-cultural, historical, and contextual determinants of health among Aboriginal peoples. Retrieved from http://www.casn.ca/2014/12/educating-nurses-address-sociocultural-historical-contextual-determinants-health-among-aboriginal-peoples/

Canadian Council on Learning (CCL). (2007). Redefining how success is measured in First Nations, Inuit and Métis learning. Retrieved from 
http://www.afn.ca/uploads/files/education/5._2007_redefining_how_success_is_measure d_en.pdf

Canadian Council on Learning (CCL). (2009). The state of Aboriginal learning in Canada: A holistic approach to measuring success. Retrieved from http://www.afn.ca/uploads/files/education2/state_of_aboriginal_learning_in_canadafinal_report,_ccl,_2009.pdf

Collins Sitler, H. (2008). Teaching with awareness: The hidden effects of trauma on learning. The Clearing House, 82(3), 119-123. http://dx.doi.org/10.3200/tchs.82.3.119-124

Council of Ministers of Education, Canada. (2010). Strengthening Aboriginal success: Summary report. Retrieved from http://www.cmec.ca/Publications/Lists/Publications/Attachments/221/aboriginal_summitr eport.pdf

First Nations Education Steering Committee. (2008). Aboriginal post-secondary education in British Columbia: A place for Aboriginal institutes. Retrieved from http://www.fnesc.ca/publications/pdf/Policy_Bkgrd_Paper_May08.pdf

Government of Canada. (2015). Research involving the First Nations, Inuit and Metis peoples of Canada. Retrieved from http://www.pre.ethics.gc.ca/eng/policypolitique/initiatives/tcps2-eptc2/chapter9-chapitre9/

Gregory, D. (2005). Aboriginal health and nursing research: Postcolonial theoretical perspectives. Canadian Journal of Nursing Research, 37(4), 11-15.

Gregory, D., \& Barsky, J. (2007). Against the odds: An update on Aboriginal nursing in Canada. Ottawa, ON: Canadian Association of Schools of Nursing. Retrieved from: http://www.naho.ca/documents/naho/english/pdf/hhr_nursing2007.pdf

Hill, D. (1999). Holistic learning: A model of education based on Aboriginal cultural philosophy (Master's thesis). Saint Francis Xavier University, Antigonish, NS. Retrieved from http://www.nvit.ca/docs/holistic\%20learning\%20a\%20model\%20of\%20education\%20ba sed\%20on\%20aboriginal\%20cultural\%20philosophy.pdf

Holmes, D. (2005). Embracing differences: Post-secondary education among Aboriginal students, students with children and students with disabilities. Montreal, QC: The Canada Millennium Scholarship Foundation. Retrieved from https://qspace.library.queensu.ca/handle/1974/5746

Indigenous Adult and Higher Learning Association (IAHLA). (2009). Transitions from Aboriginal-controlled post-secondary Institutes to public post-secondary institutions. Retrieved from http://web.uvic.ca:8080/ ocbrdev/sites/default/files/ATRP\%20Final\%20Report.pdf

Indigenous Adult and Higher Learning Association (IAHLA). (2011). Post-secondary education partnership agreement toolkit. Retrieved from http://iahla.ca/research/post-secondaryeducation-partnership-agreement-tool-kit

Juntunen, C., Barraclough, D., Broneck, C., Seibel, G., Winrow, S., \& Morin, P. (2001). American Indian perspectives on the career journey. Journal of Counseling Psychology, 
48(3), 274-285. doi:10.1037/0022-0167.48.3.274

Kulig, J., Lamb, M., Solowoniuk, J., Weaselfat, R., Shade, C., \& Hirsch-Crowshoe, H. (2010). Nurturing a dream: The support program for Aboriginal nursing students. First Nations Perspectives, 3(1), 89-106.

Malatest, R. (2010). Promising practices: Increasing and supporting participation for Aboriginal students in Ontario. Toronto, ON: The Higher Education Quality Council. Retrieved from http://heqco.ca/SiteCollectionDocuments/Promising\%20Practices.pdf

Martin, D., \& Kipling, A. (2006). Factors shaping Aboriginal nursing students' experiences. Nurse Education in Practice, 6, 380-388. http://dx.doi.org/10.1016/j.nepr.2006.07.009

Martin, D., \& Seguire, M. (2013). Creating a path for Indigenous student success in Baccalaureate nursing education. Journal of Nursing Education, 52(4), 205-209. doi:10.3928/01484834-20130314-01

McDonald, P. (2010). Transitioning from clinical practice to nursing faculty: Lessons learned. Journal of Nursing Education, 49(3), 126-131. doi:10.3928/01484834-20091022-02

Minore, B., Boone, M., Cromarty, H., Hill, M., Katt, M., Kinch, P., ... Sabourin, A. (2013). Developing supportive workplace \& educational environments for Aboriginal nurses. Thunder Bay: Centre for Rural and Northern Health Research. Retrieved from http://www.arnbccommunitiesofpractice.ca/ahnn/wpcontent/uploads/2015/04/Developing-Supportive-Workplace-Environments-ABN.pdf

Mordoch, E., \& Gaywish, R. (2013). Is there a need for healing in the classroom? Exploring trauma-informed education for Aboriginal mature students. in education, 17(3).

National Aboriginal Health Organization. (2006). Strategic framework to increase the participation of First Nations, Inuit and Métis peoples in health careers. Retrieved from http://www.naho.ca/documents/naho/english/pdf/hhr_StrategicFramework.pdf

Pewewardy, C. (1999). The holistic medicine wheel: An Indigenous model of teaching and learning. Winds of Change, 14(4), 28-31.

Pijl-Zieber, E., \& Hagen, B. (2011). Towards culturally relevant nursing education for Aboriginal students. Nurse Education Today, 31, 595-600. doi:10.1016/j.nedt.2010.10.014

Polit, D., \& Beck, C. (2012). Nursing research: Generating and assessing evidence for nursing practice (9th ed.). Philadelphia, PA: Lippincott Williams \& Wilkins.

Ramsden, I. (2002). Cultural safety and nursing education in Aotearoa and Te Waipounamu (Doctoral dissertation). Victoria University of Wellington, New Zealand. Retrieved from http://www.nzno.org.nz/services/library/theses

Smith, D., Varcoe, C., \& Edwards, N. (2005). Turning around the intergenerational impact of residential schools on Aboriginal people: Implications for health policy and practice. Canadian Journal of Nursing Research, 37(4), 38-60.

Smith, L. (2012). Decolonizing methodologies: Research and Indigenous peoples (2nd ed.). New York, NY: Zed Books Ltd. 
Smye, V., Josewski, V., \& Kendall, V. (2010). Cultural safety: An overview. Unpublished manuscript. First Nations, Inuit and Métis Advisory Committee, Mental Health Commission of Canada. Retrieved from http://www.mooddisorderscanada.ca/documents/Publications/CULTURAL\%20SAFETY \%20AN\%20OVERVIEW\%20\%28draft\%20mar\%202010\%29.pdf

Stansfield, D., \& Browne, A. (2013). The relevance of Indigenous knowledge for nursing curriculum. International Journal of Nursing Education Scholarship, 10(1), 1-9. doi:10.1515/ijnes-2012-0041.

Stonechild, B. (2006). The new buffalo: The struggle for Aboriginal post-secondary education in Canada. Winnipeg, MB: University of Manitoba Press.

Thorne, S. (2008). Interpretive description. Walnut Creek, CA: Left Coast Press, Inc.

Thorne, S., Reimer Kirkham, S., \& O'Flynn-Magee, K. (2004). The analytic challenge in interpretive description. International Journal of Qualitative Methods, 3(1), 1-21.

Usher, K., Lindsay, D., \& Mackay, W. (2005). An innovative nurse education program in the Torres Strait Islands. Nurse Education Today, 25, 437-441. doi:10.1016/j.nedt.2005.04.003

Villegas, M. (2009). This is how we "role": Moving toward a cosmogonic paradigm in Alaska Native education. Canadian Journal of Native Education, 32(1), 38-56.

Villeneuve, M., \& MacDonald, J. (2006). Toward 2020: Visions for nursing. Ottawa, ON: Canadian Nurses Association. Retrieved from http://www.cdha.nshealth.ca/search/apachesolr_search/Toward\%202010\%3A\%20visions $\% 20$ for\%20nursing

Vukic, A., Gregory, D., \& Martin-Misener, R. (2012). Indigenous health research: Theoretical and methodological perspectives. Canadian Journal of Nursing Research, 44(2), 146161.

Waldram, J., Herring, D., \& Young, T. (2006). Aboriginal health in Canada (2nd ed.). Toronto, ON: University of Toronto Press.

Wilson, A., \& Sarson, J. (2008). Literature review on participation of Aboriginal students in postsecondary health education programs in Saskatchewan. Pimatisiwin: A Journal of Aboriginal and Indigenous Community Health, 6(3), 103-127.

Wilson, D., McKinney, C., \& Rapata-Hanning, M. (2011). Retention of Indigenous nursing students in New Zealand: A cross-sectional survey. Contemporary Nurse, 38(1-2), 5975 .

Yellow Bird, M. (2013). Neurodecolonization: Applying mindfulness research to decolonizing social work. In M. Gray, J. Coates, M. Yellow Bird, \& T. Hetherington (Eds.), Contemporary social work studies: Decolonizing social work (pp. 293-310). Surrey, England: Ashgate Publishing. 